\title{
Strong microsite control of seedling recruitment in tundra
}

\author{
Bente J. Graae - Rasmus Ejrnæs • Simone I. Lang • \\ Eric Meineri $\cdot$ Pablo T. Ibarra $\cdot$ Hans Henrik Bruun
}

Received: 29 January 2010/Accepted: 1 December 2010/Published online: 19 December 2010

(C) The Author(s) 2010. This article is published with open access at Springerlink.com

\begin{abstract}
The inclusion of environmental variation in studies of recruitment is a prerequisite for realistic predictions of the responses of vegetation to a changing environment. We investigated how seedling recruitment is affected by seed availability and microsite quality along a steep environmental gradient in dry tundra. A survey of natural seed rain and seedling density in vegetation was combined with observations of the establishment of 14 species after sowing into intact or disturbed vegetation. Although seed rain density was closely correlated with natural seedling establishment, the experimental seed addition showed that the microsite environment was even more important. For all species, seedling emergence
\end{abstract}

Communicated by Bryan Foster.

Electronic supplementary material The online version of this article (doi:10.1007/s00442-010-1878-8) contains supplementary material, which is available to authorized users.

\section{B. J. Graae · E. Meineri}

Department of Ecology and Environmental Sciences,

Climate Impacts Research Centre, Umeå University,

Box 62, 98107 Abisko, Sweden

B. J. Graae ( $\square)$

Department of Biology, NTNU, Høgskoleringen 5,

7491 Trondheim, Norway

e-mail: bente.graae@bio.ntnu.no

R. Ejrnæs

Department of Wildlife Ecology and Biodiversity,

National Environmental Research Institute,

University of Aarhus, Grenåvej 12, 8410 Rønde, Denmark

S. I. Lang

Department of Systems Ecology, VU University Amsterdam,

De Boelelaan 1085, 1081 HV Amsterdam, The Netherlands peaked at the productive end of the gradient, irrespective of the adult niches realized. Disturbance promoted recruitment at all positions along the environmental gradient, not just at high productivity. Early seedling emergence constituted the main temporal bottleneck in recruitment for all species. Surprisingly, winter mortality was highest at what appeared to be the most benign end of the gradient. The results highlight that seedling recruitment patterns are largely determined by the earliest stages in seedling emergence, which again are closely linked to microsite quality. A fuller understanding of microsite effects on recruitment with implications for plant community assembly and vegetation change is provided.

Keywords Arctic - Alpine - Invasibility - Microclimate · Seed limitation

\author{
E. Meineri \\ Department of Biology, University of Bergen, \\ Allegaten 41, 5007 Bergen, Norway \\ P. T. Ibarra \\ Department of Genetics, Faculty of Biology, \\ UCM, 28040 Madrid, Spain \\ H. H. Bruun \\ Department of Ecology, Lund University, \\ Ecology Building, 22362 Lund, Sweden \\ H. H. Bruun \\ Department of Biology, Center for Macroecology, \\ Evolution and Climate, University of Copenhagen, \\ Universitetsparken 15, 2100 Copenhagen, Denmark
}




\section{Introduction}

Environmental change forces plant populations either to stay and adapt or to remain the same and colonize new areas. In both cases, sexual reproduction and regeneration from seed are essential prerequisites (Bruun and Ejrnaes 2006). Therefore, studies of seedling recruitment in natural communities—and limitations to it—are needed. Seedling recruitment in tundra communities is of particular interest because of the predicted high impact of climate change on this ecosystem (Sala et al. 2000). Furthermore, the tundra is dominated by long-lived, often clonally propagating species, where recruitment by seeds is expected to be rare. These species and communities are thus particularly vulnerable to environmental changes.

In previous studies of seedling recruitment, two different approaches have prevailed: direct observation of naturally occurring seedlings in different communities, and seed addition experiments, sometimes combined with manipulation of environmental conditions. In observational studies, the drivers of observed patterns in natural seedling occurrence are often difficult to disentangle because factors co-vary (e.g., Welling and Laine 2000; Forbis 2003). The manipulative studies can overcome this problem by assessing the effect of a single variable in turn. However, such studies are bound to test only one or two variables, and, once an effect has been found, how it relates to natural biotic and abiotic conditions often remains unclear. Thus, seed addition studies most often report increased seedling emergence, and conclude that seed availability limits recruitment (Myers and Harms 2009). There is, however, growing appreciation that many experiments are made without reference to the background level of seed rain, and that such results may underestimate the effect of microsite limitation (e.g., Clark et al. 2007). Furthermore, seed and microsite limitation experiments are most often carried out in single communities, in spite of expectations of a shifting balance between these opposed types of recruitment limitation along gradients (Foster et al. 2004; Stevens et al. 2004; Brooker et al. 2008). Therefore, we use a novel approach that combines data on background seed rain and the densities of naturally occurring seedlings and seedlings emerging as a result of seed addition to intact vegetation and to experimental competition-released gaps along a gradient of environmental severity in tundra vegetation.

In dry tundra vegetation, plant communities are typically distributed along an environmental gradient running from wind-exposed ridges to more sheltered depressions (Billings and Mooney 1968; Bruun et al. 2006). Ridges have little or no snow cover during the winter and hence experience harsh conditions with low winter temperatures, strong winds, a coarse soil texture and an unreliable water supply, but also a long growing season (Körner 2003). In contrast, depressions have less severe environmental conditions, with more snow cover, greater protection from the wind, soils with better moisture and nutrient statuses, but also a shorter growing season (Choler 2005). In deeper depressions with very late snow melt and water-logged soils, stress levels tend to increase again and limit productivity. The density of seedlings varies dramatically, with most seedlings in vegetation of moist habitats and very few seedlings in heaths or growing under harsh environmental conditions (Chambers 1995a; Welling and Laine 2002; Forbis 2003; Gough 2006). Seed rain also varies (Molau and Larsson 2000) depending on seed production, topography, and how the vegetation structure and soil surface affects seed interception (Chambers et al. 1991; Aguiar and Sala 1997). Recent studies demonstrate that recruitment increases as a result of seed addition (Gough 2006; Klanderud and Totland 2007; Lindgren et al. 2007). While the mentioned studies also document microsite limitation, how microsite quality contributes to the patterns of varying seedling density along gradients of environmental harshness remains to be quantified.

Limited recruitment, despite sufficient availability of germinable seeds, may be related to microclimatic factors such as temperature, moisture and length of the growing season, or to biotic interactions at microsites, such as herbivory or competition with established vegetation (Turnbull et al. 2005). The extant vegetation furthermore modifies the microsites through the litter layer and through its impact on the microclimate (Suding and Goldberg 1999; Venn and Morgan 2009). Under stressful microclimatic conditions, facilitation by neighboring plants has often been recorded, whereas competition may increase as the microclimate becomes more benign (Tielbörger and Kadmon 2000; Brooker et al. 2008). For seedling recruitment, one recent study testing the balance between facilitation and competition in rather harsh climates found no evidence for strong facilitation (Klanderud and Totland 2007), whereas other studies documented the facilitation by neighboring plants of seedling recruitment above the tree line (Germino et al. 2002), as well as at lower elevations (Cavieres et al. 2006).

Establishment limitation may be related to the different physiological processes associated with breaking seed dormancy, seed germination, and seedling survival. High seedling mortality has often been associated with harsh environments (Moles and Westoby 2004), whereas to our knowledge only a few studies have examined the relationship between microclimate and seedling emergence in tundra species (Cavieres et al. 2007; Klanderud and Totland 2007; Graae et al. 2009; Shevtsova et al. 2009).

In the present study we combine data on seed rain, densities of naturally occurring seedlings (spontaneous seedlings), and seedlings emerging after seed addition in 
intact vegetation and in gaps along a gradient of increasing environmental severity in tundra vegetation. We aimed to answer the following questions. (1) Is seed or microsite limitation driving early recruitment patterns in tundra ecosystems? (2) Is seedling recruitment increasingly facilitated by vegetation cover with environmental severity? (3) Does the regeneration niche vary between species? (4) What is the most decisive phase for early recruitment: germination, summer survival or winter survival?

\section{Materials and methods}

\section{Study site}

The field study was carried out between autumn 2005 and summer 2007 at $68^{\circ} 17^{\prime} \mathrm{N}, 18^{\circ} 45^{\prime} \mathrm{E}$ close to Tältlägret, $8 \mathrm{~km}$ south of the Abisko Scientific Station, Northern Sweden. The 1961-1990 average annual temperature in Abisko was approximately $-0.8^{\circ} \mathrm{C}$. July is on average the warmest month $\left(+11^{\circ} \mathrm{C}\right)$ and January the coolest $\left(-11.9^{\circ} \mathrm{C}\right)$. Mean annual precipitation for the period 1961-1990 was $304 \mathrm{~mm}$ (Alexandersson and Eggertsson Karlström 2001). While Abisko is situated in the forested area dominated by Betula pubescens ssp. tortuosa, the study site is above the treeline between 650 and 800 m.a.s.l. Reindeer are known to graze throughout the area.

Large parts of the alpine landscape consist of heaths, mainly dominated by the dwarf shrubs Empetrum hermaphroditum, Vaccinium vitis-idaea, Vaccinium uliginosum and Betula nana. In depressions with prolonged snowcover, characteristic snowbeds appear with a relatively rich herbaceous vegetation with, for instance, Viola biflora, Saussurea alpina, Sibbaldia procumbens, and Gnaphalium supinum. Downslope from these, often associated with abundant access to water, Salix scrubs or thickets appear that -if not too closed-may harbor a rich understory of herbaceous species too.

\section{Sampling and experimental design}

All plots were established on 29 and 30 September 2005. In order to uniformly sample the environmental gradient, from wind-swept ridges to depressions with prolonged snow cover, we applied a stratified random distribution of sample plots. Four sites, typically $200 \mathrm{~m}$ from each other, were selected; at each site, one plot was randomly positioned in each of five community types: lichen heath (on ridges), poor dwarf-shrub heath (with sparse vegetation cover), rich dwarf-shrub heath (with taller and denser dwarf-shrub cover), herb field (meadow-like moderate snowbed) and willow (Salix glauca) scrub. There were no signs of larger gaps or disturbances in the vegetation when these plots were established. One plot that appeared to represent lichen heath during plot establishment turned out to be waterlogged during the growing season, with a species composition deviating clearly from other lichen heath plots. Data from this plot were therefore omitted from the analyses. Each plot consisted of one central permanently marked main quadrat $(0.5 \times 0.5 \mathrm{~m})$ and three adjacent quadrats (Fig. 1). For each plot, a sister plot $(0.5 \times 0.5 \mathrm{~m})$ that was within $10 \mathrm{~m}$ of the main plot-and was as similar as possible to it in terms of vegetation structure, species composition, exposure and slope-was selected, where destructive sampling of biomass could be done without interfering with recruitment monitoring.

In each plot, a $10 \times 20 \mathrm{~cm}$ subplot located in one corner (Fig. 1) was disturbed mechanically. All living plant tissue above- and belowground (to a depth of $10 \mathrm{~cm}$ ) was removed from this subplot. If needed, soil from just outside the plot was added and mixed with the original soil in order to maintain the same surface level as the surroundings. Another $10 \times 20 \mathrm{~cm}$ area that was undisturbed was located in a different corner (Fig. 1). Half of each subplot $(10 \times 10 \mathrm{~cm})$ was used for the seed addition experiment, and the other half was used to assess nutrient availability (see below).

\section{Seed rain and spontaneous seedlings}

Six seed traps (each comprising a $7.5 \times 55 \mathrm{~cm}^{\text {FinnTurf }}{ }^{\mathrm{TM}}$ doormat) were placed around each main quadrat from early August and left in place until early October 2006 (Fig. 1). This type of seed trap has been previously used in arctic studies (e.g., Molau and Larsson 2000). We decided to use six narrow strips rather than one broad rectangle in order to allow us to place seed traps below the seed-producing

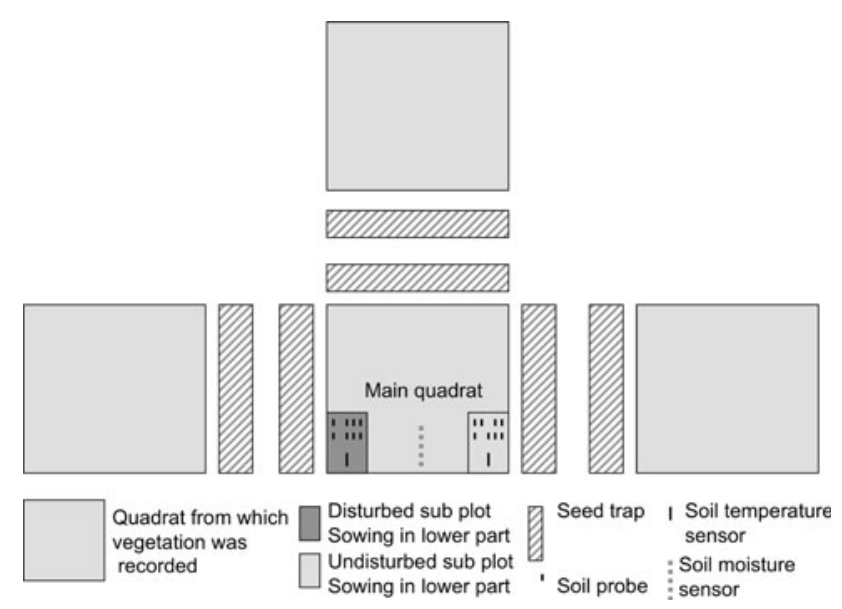

Fig. 1 Diagrammatic representation of the plot layout. Vegetation cover was recorded in the four quadrats (each $0.5 \times 0.5 \mathrm{~m}$ ). The seed sowing experiment and measurements of abiotic variables were done in subplots located within the central (main) quadrat 
plants with a minimum of physical disturbance. Upon collection, traps were taken to the laboratory in sealed plastic bags, where they were dried and carefully cleaned. The content of each trap and the plastic bag was analyzed under a dissecting microscope, and plant propagules (seeds and bulbils) were sorted to species. In the present paper, we used the total number of diaspores (including bulbils) from the six traps around each plot as an estimate of seed rain density.

Spontaneous seedlings (defined here as individuals that appeared to have emerged naturally from seeds or bulbils within the same season) were recorded in each main quadrat by searching the undisturbed part of the vegetation carefully on one occasion in mid-August 2006. If fewer than 20 seedlings were found inside the main quadrat, we continued searching, first in the sister plot, then in additional nonoverlapping $0.5 \times 0.5 \mathrm{~m}$ quadrats in the surrounding similar vegetation, until at least 20 seedlings had been recorded or we had searched a total area of $5 \mathrm{~m}^{2}$. Seedling density was calculated as the seedling number per $\mathrm{m}^{2}$.

\section{Environmental variables}

A temperature sensor (an Onset 8-bit Temperature Smart sensor) was inserted below each subplot at a soil depth of ca. $2 \mathrm{~cm}$. A soil moisture sensor (ECH2O Dialectric Aquameter, Decagon Devices, Inc., Pullman, WA, USA) was inserted at a soil depth of ca. 3-5 cm between the two subplots. The sensors were connected to a HOBO Micro Station Data Logger (Onset Computer Corporation) outside the plot, which recorded temperature and moisture levels every $2 \mathrm{~h}$ from the onset of the growing season 2006 until snowmelt in 2007. All data loggers worked from June to August, but five loggers (one lichen, two poor dwarf shrubs, one herb field and one willow scrub) were damaged due to waterlogging during the winter period. Data from these plots were omitted from analyses involving winter temperatures and duration of snow cover.

In disturbed and undisturbed subplots, four anion exchange membranes and four cation exchange membranes [IEM; Plant Root Simulator ${ }^{\mathrm{TM}}$ (PRS)-probes] were inserted into the top $5 \mathrm{~cm}$ of the soil (Fig. 1). These probes were collected after 6 weeks (3 August to 14 September), washed thoroughly with demineralized water (MilliQ), and shipped to the analytical laboratory (Western Ag Innovations) to extract ions and for subsequent analysis. Ions were extracted with $17.5 \mathrm{ml}$ of $0.5 \mathrm{~mol} / 1 \mathrm{HCl}$ per probe. Inorganic nitrogen $\left(\mathrm{NH}_{4}{ }^{+}-\mathrm{N}\right.$ and $\left.\mathrm{NO}_{3}{ }^{-}-\mathrm{N}\right)$ was determined by colorimetry using a Technicon Autoanalyzer II (TIC 1977). The $\mathrm{NO}_{3}{ }^{-}-\mathrm{N}$ analysis was slightly modified through the addition of $\mathrm{NaOH}$ to the $\mathrm{NH}_{4} \mathrm{Cl}$ reagent 8 (adjusting the $\mathrm{pH}$ to 8.5 ) in order to neutralize the sample solution before its entry into the Cd-reduction column (Western Ag Labs 2003). The remaining elements ( $\mathrm{P}, \mathrm{K}, \mathrm{S}, \mathrm{Ca}, \mathrm{Mg}, \mathrm{Al}, \mathrm{Fe}$, $\mathrm{Mn}, \mathrm{Cu}, \mathrm{Zn}$ and $\mathrm{B}$ ) were measured by ICP (inductively coupled plasma; Optima 3000-DV ICP, PerkinElmer Inc., Shelton, CT, USA). All standards and controls were prepared in a $0.5 \mathrm{~mol} / \mathrm{l} \mathrm{HCl}$ matrix, equivalent to that of the sample extracts. Unused PRS probes also were eluted and analyzed as a blank test for contamination during handling.

We calculated mean, minimum and maximum temperatures for June (spring) and July-August (summer) and the minimum temperature for February-March (winter). Mean soil moisture was calculated for the period July-August 2006, and spring moisture for the period May-June 2007.

Vegetation data were obtained in August 2006 by recording the presence of species at a scale of $1 \mathrm{~m}^{2}$. Vascular plants were determined in the field, while bryophytes and lichens were generally collected for later identification in the laboratory. Soil depth in the plot was estimated by measuring (to the nearest $\mathrm{cm}$ ) the depth to which a pointed steel rod $(2.5 \mathrm{~mm} \varnothing)$ could be forced vertically into the soil by hand (average of 20 insertions). This estimate provides an index for the available productive soil volume, as the rod would naturally be obstructed by stones as well as by solid bedrock.

In the sister plots, the aboveground biomass from four different $10 \times 10 \mathrm{~cm}$ areas was harvested and brought back to the laboratory. The samples were carefully sorted according to species and, for vascular plant species and most importantly for the dwarf shrub and shrub species, divided into the current years' production and the previous years' production in order to estimate the annual net primary production (NPP). The samples were subsequently dried $\left(40^{\circ} \mathrm{C},>2\right.$ months) and weighed. Samples were collected from the underlying $10 \mathrm{~cm}$ of soil (hence $10 \times 10 \times 10 \mathrm{~cm})$ and soil organic matter content was estimated by loss on ignition $\left(5 \mathrm{~h}\right.$ at $\left.550^{\circ} \mathrm{C}\right)$ as well as the $\mathrm{pH}$ as measured in a water solution.

\section{Seed addition experiment}

Each $10 \times 10 \mathrm{~cm}$ subplot (undisturbed or disturbed) was divided into 16 microplots of $2.5 \times 2.5 \mathrm{~cm}$. In these microplots, 30 seeds of each of 14 species belonging to different growth forms and with different main occurrences along the gradient (Table 1) were placed on the surface, with a single species allocated randomly to each microplot. The seed addition thus corresponded to 42,000 seeds per $\mathrm{m}^{2}$, which is well above normal seed rain in these communities (Molau and Larsson 2000) and should saturate the communities with seeds. All seeds were collected in the study region during the month before sowing and stored at room temperature, except for fleshy fruits, which were stored at $5^{\circ} \mathrm{C}$ whilst awaiting seed extraction. Seeds were 
sown on 29 and 30 September 2005. Seedling emergence was recorded immediately after snowmelt (25 May for most plots, but 8 June for late-melting plots, i.e., one Salix plot and all four herb plots) and repeated on 29 June, 13 July, 27 July and 14 August. The seedlings in the plots were recorded again on 16 July in 2007.

To determine if seed quality affected recruitment, and how the dormancy patterns of the species affect recruitment in the field, the germinability of the seeds was tested in incubation chambers. For each species, six Petri dishes were prepared, each with 30 seeds on moist filter paper (Munktell 00A). Three dishes were placed directly in warm incubation conditions for 6 weeks, with a light and temperature regime of $14 \mathrm{~h}$ light $\left(240 \mu \mathrm{mol} / \mathrm{m}^{2} / \mathrm{s}\right) / 20^{\circ} \mathrm{C}$ and $10 \mathrm{~h}$ dark $/ 10^{\circ} \mathrm{C}$ followed by cold stratification $\left(2^{\circ} \mathrm{C}\right.$ and darkness) for 20 weeks and another 6 weeks of warm incubation. The number of germinated seedlings obtained from these treatments provided two sets of germination percentages: (1) warm incubation (W), and (2) warm + cold + warm incubation $(\mathrm{W}+\mathrm{C}+\mathrm{W})$. The remaining three dishes prepared for each species were immediately cold stratified for 20 weeks before 6 weeks of warm incubation. The number of seeds that germinated during this trial gave the third set of germination percentages: (3) cold + warm incubation $(\mathrm{C}+\mathrm{W})$.

Data analysis

\section{Community composition}

The qualitative data on community composition including all photosynthesizing organisms (vascular plants, bryophytes and macrolichens) from the $19.1 \mathrm{~m}^{2}$ plots were analyzed using nonmetric multidimensional scaling (NMS) (McCune and Grace 2002). We ran 1,000 NMS trials with one, two, and three dimensions. The onedimensional solution explained $86 \%$ of the variation in the original plot-by-plot distance matrix (using Sørensen dissimilarity), whereas the two-dimensional NMS explained $94 \%$ of the variation. The one-dimensional NMS and the first axis of a DCA ordination were nearly identical $\left(r^{2}=0.99\right)$, providing strong evidence of a single major vegetation gradient in the studied sites, and we decided to use the one-dimensional NMS to represent

Table 1 Germination percentages of the species in the seed addition experiment, ranked by germination capacity

\begin{tabular}{|c|c|c|c|c|c|c|c|}
\hline & Growth form & Common habitats & $\mathrm{W}$ & $\mathrm{W}+\mathrm{C}+\mathrm{W}$ & $\mathrm{C}+\mathrm{W}$ & Disturbed & Undisturbed \\
\hline \multicolumn{8}{|c|}{ High germination rates of fresh seeds } \\
\hline Cerastium alpinum & $\mathrm{f}$ & $\mathrm{P}, \mathrm{S}, \mathrm{H}$ & 100 & 100 & 99 & 25.3 & 1.8 \\
\hline Deschampsia flexuosa & $\mathrm{g}$ & $\mathrm{R}, \mathrm{H}$ & 97 & 97 & 91 & 25.6 & 2.1 \\
\hline Festuca ovina & $\mathrm{g}$ & $\mathrm{R}, \mathrm{H}$ & 94 & 94 & 96 & 19.3 & 3 \\
\hline Salix herbacea & $\mathrm{dd}$ & $\mathrm{H}$ & 93 & 93 & 81 & 0.3 & 0 \\
\hline Vaccinium myrtillus & $\mathrm{dd}$ & $\mathrm{R}, \mathrm{H}$ & 52 & 53 & 58 & 5.6 & 0.4 \\
\hline Silene acaulis & $\mathrm{f}$ & $\mathrm{L}, \mathrm{P}$ & 60 & 64 & 78 & 37.5 & 3.7 \\
\hline Dryas octopetala & $\mathrm{dd}$ & $\mathrm{L}, \mathrm{P}$ & 44 & 51 & 51 & 10 & 4 \\
\hline \multicolumn{8}{|c|}{ Increased germination after cold stratification } \\
\hline Salix glauca & $\mathrm{s}$ & $\mathrm{R}, \mathrm{S}$ & 18 & 87 & 86 & 3.3 & 0 \\
\hline Betula nana & $\mathrm{dd}$ & $\mathrm{R}$ & 43 & 70 & 68 & 9.3 & 0.4 \\
\hline Sibbaldia procumbens & f & $\mathrm{H}$ & 1 & 68 & 0 & 7 & 0.6 \\
\hline Gnaphalium supinum & f & $\mathrm{H}, \mathrm{S}$ & 21 & 47 & 14 & 3.4 & 0 \\
\hline \multicolumn{8}{|c|}{ Germination failed in incubators } \\
\hline Empetrum hermaphroditum & ed & $\mathrm{P}, \mathrm{R}$ & 0 & 0 & 0 & 0.5 & 0 \\
\hline Vaccinium uliginosum & $\mathrm{dd}$ & $\mathrm{L}, \mathrm{P}, \mathrm{R}$ & 0 & $0^{\mathrm{a}}$ & $0^{\mathrm{a}}$ & 17.5 & 1.4 \\
\hline Vaccinium vitis-idaea & ed & $\mathrm{R}$ & 0 & $0^{\mathrm{a}}$ & $0^{\mathrm{a}}$ & 14.4 & 0.2 \\
\hline Average & & & 45 & 59 & 51 & 12.8 & 0.9 \\
\hline
\end{tabular}

Germination percentages shown are those observed when the species was tested in vitro after 6 weeks of warm incubation (W) followed by 20 weeks of cold stratification and another 6 weeks of warm incubation $(\mathrm{W}+\mathrm{C}+\mathrm{W})$. The third column gives germination percentages of seeds that had 20 weeks of cold stratification followed by 6 weeks of warm incubation $(C+W)$. The last two columns give average germination percentages in disturbed and undisturbed vegetation calculated from the maximum number of emerged seedlings in each plot, observed after sowing in the field. The growth form and the common habitats for each species are indicated

Growth form: $d d$ deciduous dwarf shrub, $e d$ evergreen dwarf shrub, $f$ forb, $g$ graminoid and $s$ shrub. Common habitats: $H$ herb dominated, $L$ lichen heath, $P$ poor dwarf shrub dominated heath, $R$ rich dwarf shrub dominated heath, $S$ Salix scrub

a Seeds were attacked by fungi during the treatments 
the dominant gradient. Spearman rank correlation was used to investigate the relationships between NMS-1, measured environmental variables, and seedling densities and mortalities.

\section{Spontaneous recruitment}

The effects of seed rain density and environmental variability on the density of spontaneous seedlings were tested using a multiple linear regression. Seedling density was log-transformed to obtain normally distributed errors. We used NMS-1 as a proxy for the primary environmental gradient in our study, acknowledging the multivariate nature of this gradient with a large number of highly correlated climatic and soil variables (see "Results").

\section{Experimental recruitment}

To investigate the critical stages in recruitment, we divided the process into four stages: (1) seedling emergence; (2) summer mortality; (3) winter mortality; and (4) second-year emergence. We used Pearson product moment correlation to evaluate which of these stages contributed the most to determining the between-plot variation in final recruitment. The low number of germination events in the undisturbed plots prevented quantitative analysis, so only data from disturbed plots were included. For the same reason, correlation analyses between environmental variables and recruitment, emergence and mortalities in the plot were only conducted for disturbed plots.

The seedling recruitment (defined as the number of individuals that emerged from added seeds and then survived until July 2007, i.e., 22 months after sowing) in the experimental microplots was examined in response to three sources of variation: (1) the position of the plot along the studied environmental gradient (NMS-1); (2) the species sown (Table 1); and (3) the disturbance factor (intact or disturbed vegetation). We also tested for interactions between treatments as indicators of non-neutral processes. An interaction between disturbance and NMS-1 would indicate net facilitation or net competition, whereas an interaction between species and NMS-1 or disturbance would indicate that the species had different regeneration niches (Grubb 1977). We analyzed recruitment using a GLM with Poisson-distributed errors. The individual terms were added sequentially, with the term explaining most variation added first. The significances of all individual and interaction terms were tested using 20-fold cross-validation (Ripley 1996). Candidate variables that did not improve the cross-validated prediction of the model (evaluated by Pearson product moment correlation between predicted and observed recruitment) were considered nonsignificant.
E. hermaphroditum and Salix herbacea were omitted from this analysis since recruitment was too low (2-3 individuals recruited across the whole experiment).

Differences in temperature and ion supply rates between disturbed and undisturbed subplots (variables that were measured in both subplot types) were analyzed using the Wilcoxon signed rank comparison for paired observations.

Nomenclature follows Krok and Almquist (1994). PCOrd v.4.41 (McCune and Mefford 1999) was used for ordination and S-Plus 2000 (MathSoft 1999) was used for plotting, GLM, ANOVA, and correlation.

\section{Results}

The environmental gradient

The gradient described by the NMS-1 placed lichen heath at one end of the axis, followed by poor heath, rich heath, herb field, and Salix scrub. NPP estimates of vascular plants ranged from $18 \mathrm{~g} \mathrm{~m}^{-2}$ in lichen heath to $670 \mathrm{~g} \mathrm{~m}^{-2}$ in Salix scrub, and NMS-1 was strongly associated with this gradient ( $\rho=0.80, P=0.0006$ ), with peak values for the Salix scrub, but also with a small secondary hump in the middle of the axis, resulting from the relatively high NPP of rich dwarf shrub heath (see the Electronic supplementary material, ESM). Cryptogam standing crop was inversely related to the gradient ( $\rho=-0.64, P=0.0070)$, ranging from $29 \mathrm{~g} \mathrm{~m}^{-2}$ in Salix scrub to $221 \mathrm{~g} \mathrm{~m}^{-2}$ in lichen heath. Minimum winter temperature $2 \mathrm{~cm}$ below the soil surface ranged from $-23^{\circ} \mathrm{C}$ on wind-swept ridges with lichen heath to just below zero in herb field and Salix scrub. Soil depth $(\rho=0.63, P=0.0078), C a$ supply rate ( $\rho=0.65, P=0.0054)$, and winter minimum temperature ( $\rho=0.87, P=0.0016)$ all increased along the gradient (ESM 1). Soil pH was typically around 4 in heath and between 5 and 7 in the Salix scrub and herb field. Based on this interpretation, we refer to NMS-1 as the environmental gradient in the following, acknowledging that vegetation composition and productivity as well as soil moisture, available nutrients, $\mathrm{pH}$, soil volume, and microclimate all correlate with and contribute to this complex gradient. The ESM 2 shows the distribution of biomass among the ten most abundant species in each community.

Seed rain and spontaneous seedlings along the gradient

The density of spontaneous seedlings was closely correlated with the environmental gradient and ranged from 42.7 seedlings per $\mathrm{m}^{2}$ at the productive end of the gradient to 1.3 at the unproductive end. The seed rain was highest in the herb field and Salix scrub (Fig. 2a). The number of 

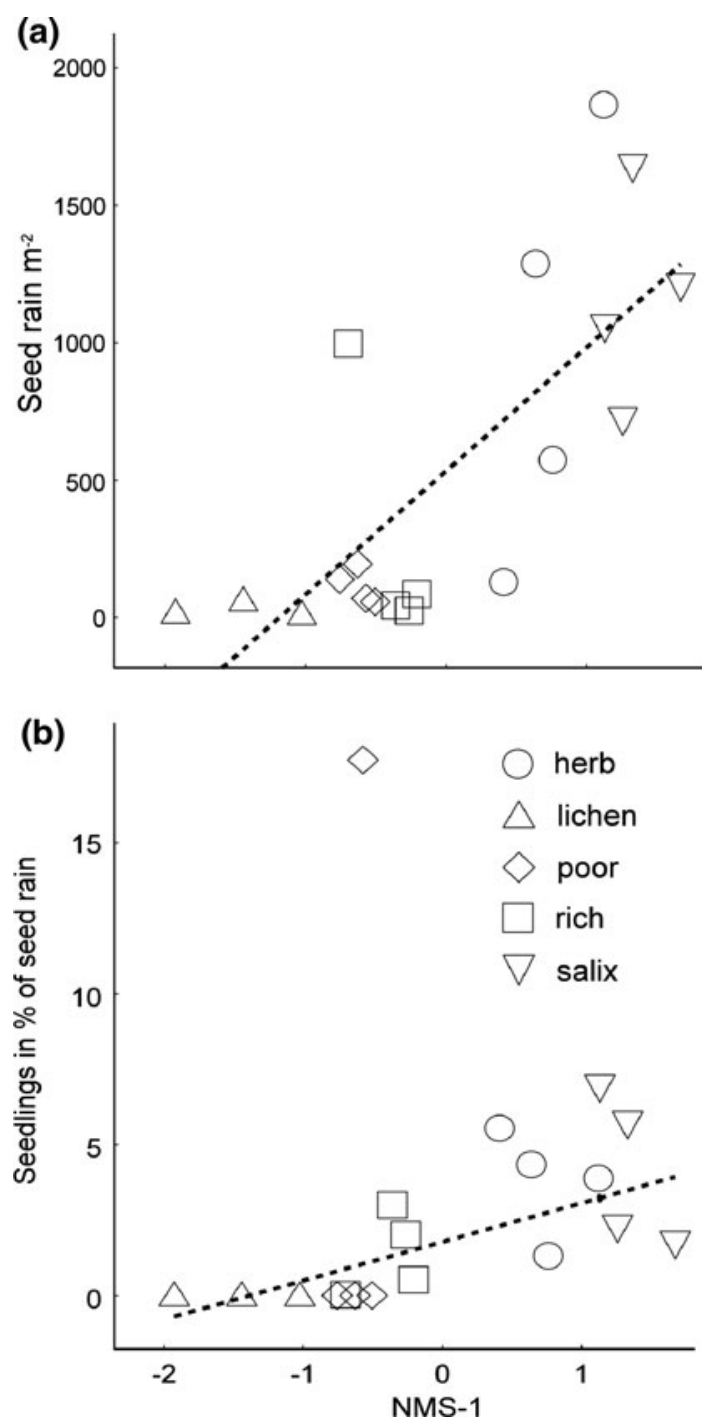

Fig. 2 Relationships between the multivariate environmental gradient (NMS-1) and a seed rain and $\mathbf{b}$ the proportion of the seed rain that emerged as spontaneous seedlings. Data for each community type are indicated by symbols. Linear regression lines shown a $r^{2}=0.55$, $P=0.0004, n=19$, and $\mathbf{b} r^{2}=0.48, P=0.0014, n=18$ (excluding one outlier)

spontaneous seedlings expressed as a percentage of seed rain was positively correlated with NMS-1, and ranged from 0 to $5 \%$, with one outlying plot from the poor lichen community (Fig. 2b).

In a multiple regression, NMS-1 and seed rain explained $79 \%$ of the variation of the density of spontaneous seedlings $(P<0.001)$. Evaluations using sequential (type I) or unique (type III) sums of squares revealed that most of the variation was shared between the two variables, but also that both variables explained a significant part of the variation in seedling density, even after taking the other variable into account (NMS-1: 13\%, seed rain: $7 \%$ and shared: $59 \%$ ).
The importance of disturbance, environmental gradient and sown species for recruitment

The GLM of recruitment from added seeds, as a function of disturbance, species and environment, revealed that significant effects were associated with each explanatory factor (Table 2). Disturbance had by far the strongest effect, with 34 times as many seedlings emerging on average after disturbance. There were also strong effects of species (11.8 times more seedlings for Deschampsia flexuosa than for Dryas octopetala) and NMS-1 (4.5-fold increase in seedling numbers from the unproductive to the productive end of the gradient). Despite slightly lower residual deviance and AIC (Akaike information criterion) values, none of the interactions improved the cross-validated predictions of the model. Therefore, we were unable to find a significant change in the effect of disturbance along the environmental gradient (such a change would have indicated a change in facilitation/competition along the gradient), and also no significant species-specific variation in the patterns of recruitment along the gradient (which would have indicated species-specific regeneration niches).

We observed overdispersion in data, and were also concerned about zero inflation. Both model violations may explain why the cross-validation test appeared to be more conservative in model complexity than AIC and residual deviance. To check that model coefficients were reliable, we performed both a GLM and a zero-altered model assuming a negative binomial distribution (Zuur et al. 2009). However, the predictions of these models were not superior to the selected GLM, and they produced very similar results, with model coefficients correlating strongly with the reported set ( $r=0.98$ and $r=0.96$, respectively).

Spontaneous and experimental seedling densities from undisturbed vegetation were not significantly correlated, possibly due to the very low number of experimental seedlings in the undisturbed vegetation. However, seedling density in disturbed subplots was positively correlated with spontaneous seedling density $(\rho=0.72, P=0.0025)$.

Generally, the correlations between environmental variables and recruitment in the disturbed subplots mirrored the correlations with NMS-1. In particular, soil depth, snowmelt timing, winter temperatures, and the supply rates of $\mathrm{Ca}$ and $\mathrm{Cu}$ were positively correlated with both natural and sown seedling emergence (all $\rho>0.6, P<0.05$ ). Nitrate and ammonium supply rates appeared to exert opposite effects on spontaneous recruitment, with nitrate having a positive effect $(\rho=0.49, \quad P=0.038)$ and ammonium a negative effect $(\rho=-0.49, P=0.037)$. Nitrate was also positively correlated with the emergence of sown seeds $(\rho=0.60, P=0.011)$ but not with recruitment after 2 years $(\rho=0.36, P=0.12)$. In general, 
Table 2 Summary of an ANOVA showing the results of a Poisson regression (GLM) of seedling recruitment (survival to the second growing season) in response to disturbance, sown species and environmental gradient

\begin{tabular}{|c|c|c|c|c|c|}
\hline Variable & $d f$ & $\begin{array}{l}\text { Explained } \\
\text { deviance }\end{array}$ & $\begin{array}{l}\text { Residual } \\
\text { deviance }\end{array}$ & AIC & Cross-validated $r^{2}$ \\
\hline Intercept & 1 & & & & \\
\hline Disturbance & 1 & 672 & 1270 & 1274 & 0.168 \\
\hline+ Species & 11 & 254 & 1016 & 1042 & 0.245 \\
\hline + NMS-1 & 1 & 100 & 916 & 944 & 0.297 \\
\hline+ Species $\times N M S-1$ & 11 & 112 & 804 & 854 & 0.287 \\
\hline+ Species $\times$ disturbance & 11 & 28 & 888 & 938 & 0.293 \\
\hline$+N M S-1 \times$ disturbance & 1 & 7 & 909 & 939 & 0.296 \\
\hline
\end{tabular}

The effects of the interaction terms were evaluated individually, one at a time, in the basic model. The consumed degrees of freedom $(d f)$, the explained deviance, the residual deviance after adding the variable, and the cross-validated $r^{2}$ from a correlation between cross-validated predictions and observed recruitment are provided

the total number of seedlings emerging in the first summer after sowing was more closely correlated to soil variables than was final recruitment after 2 years. Summer and winter mortality exhibited contrasting relationships with the environmental gradient $(\rho=-0.49, P=0.060$ for summer mortality and $\rho=0.55, P=0.056$ for winter mortality; only plots in which more than five seedlings entered the relevant stage were included in the analysis). Winter mortality increased with later snowmelt ( $\rho=0.87$, $P=0.0094)$ and higher winter temperature $(\rho=0.86$, $P=0.011)$. On average, $51 \%$ of seedlings in the Salix scrub and $65 \%$ in the herb field died during the first winter, compared to only $13 \%$ in lichen and dwarf shrub heath. The highest mortality was recorded for $D$. octopetala (82\%), B. nana (62\%) and Silene acaulis (61\%). For D. octopetala and S. acaulis, the mortality was particularly high at the most productive end of the gradient (Fig. 3a,b). D. flexuosa (25\%, Fig 3g) and Festuca ovina (45\%, Fig. 3i) exhibited the lowest mortalities.

Significant differences in microclimate between disturbed and undisturbed subplots were found. Disturbed subplots had more pronounced temperature extremes and significantly increased supply rates of $\mathrm{Ca}, \mathrm{Fe}$ and $\mathrm{S}$. However, the differences caused by disturbance were relatively small compared to the between-plot variations in these factors, so they could not explain the differences in recruitment between the two subplot types.

The decisive phase in early recruitment

Laboratory screening of seed germinability showed (Table 1) that all species, except for E. hermaphroditum, $V$. uliginosum and $V$. vitis-idaea, had relatively high germination rates $(47-100 \%$ in at least one treatment). Sibbaldia procumbens needed warm + cold + warm stratification before germination occurred. The lack of in vitro germination of the two Vaccinium species could be attributed to fungal attack during the required stratification treatment (Baskin et al. 2000), and experimentally sown seed did indeed germinate under field conditions.

Emergence from sown seeds was relatively common in the disturbed subplots (average emergence $=12.8 \%$ ) and all sown species emerged in at least one microplot. In undisturbed plots, 12 out of 14 species emerged in at least one undisturbed microplot during the course of the experiment but the emergence was much lower, averaging $0.9 \%$ (Table 1).

Of all sown seeds, $7.2 \%$ were subsequently recorded as being "recruited". The most successful recruitment in disturbed microplots was observed for S. acaulis (26.5\%), Cerastium alpinum (19.1), and D. flexuosa (17.2\% of all sown seeds). V. uliginosum and V. vitis-idaea showed intermediate emergence percentages (17.6 and 14.3\%, respectively; the numbers for recruitment were 12.4 and 11.6 for these species) in the field, despite their failure to germinate in vitro, whereas $S$. glauca and S. herbacea showed very poor performance in the field despite good germination in vitro. Hence, the germinability of the seeds used is not likely to have affected the recruitment patterns significantly. Note that the break in dormancy requirement for $S$. procumbens was clearly seen in its emergence pattern in the field (Fig. 3h).

In contrast to the recruitment in disturbed vegetation, the mean recruitment in undisturbed subplots in the second year was only $0.2 \%$, and only C. alpinum, D. flexuosa and $F$. ovina were still present at that time.

We analyzed the contributions of four temporal stages (first-year emergence, \% summer mortality, \% winter mortality and second-year emergence) to second-year recruitment in disturbed subplots. Correlation with final recruitment was significant for all stages $(R=0.86,-0.63$, -0.27 , and 0.70 , respectively). Summer mortality reinforced the environmental gradient patterns in germination (correlation with NMS1: $R=-0.58, P=0.014$ ), whereas 

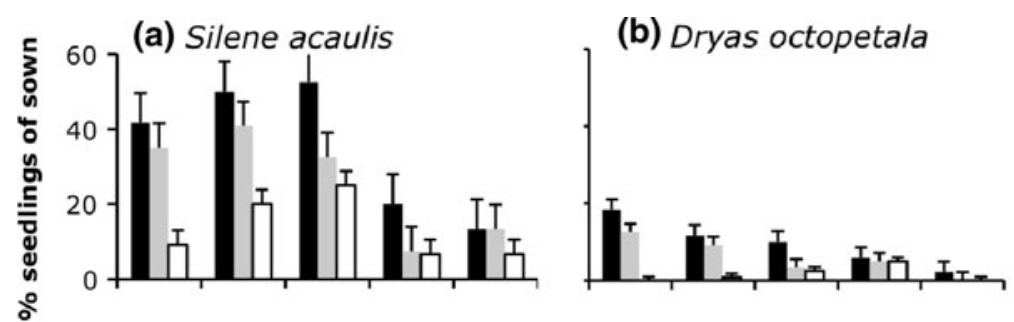

(e) Betula nana
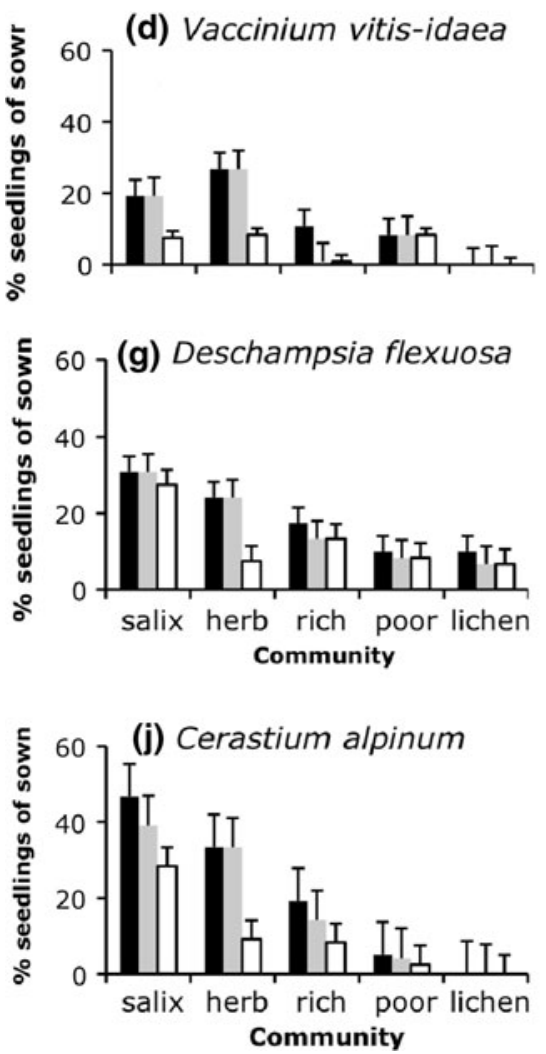

Fig. 3 Percentage of seedlings (mean + SE) observed in seed addition microplots in each community. Black bars are the maximum percentage of all sown seeds emerging during the first growing season, gray bars show the percentage of all sown seeds surviving to the end of the first growing season, and white bars indicate the percentage of all sown seeds surviving to the second growing season.

winter mortality worked in the opposite manner $(R=0.43$, $P=0.13$ ), with the highest mortality occurring at the productive end of the gradient (see also above).

\section{Discussion}

By combining background seed rain density, spontaneous seedling density and experimental seed addition along a gradient in environmental severity, we were able to disentangle the effects of important environmental factors on patterns of seedling recruitment. High between-community variation in seed rain density was demonstrated. Spontaneous seedling density corresponded to as little as $0.25 \%$ of

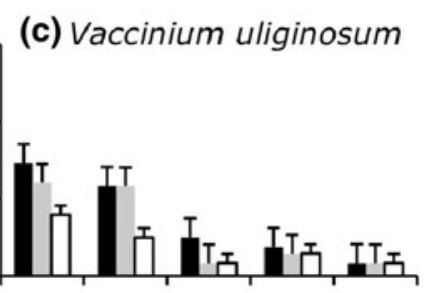

(f) Vaccinium myrtillus
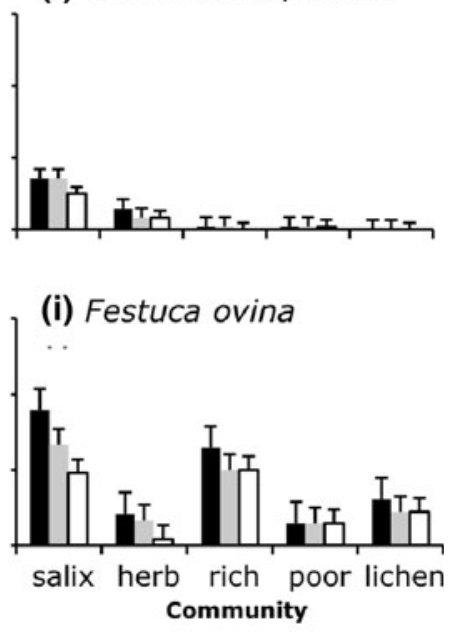

The species are ordered with respect to their occurrence along the environmental gradient: a Silene acaulis and b Dryas octopetala occurring mostly in the least productive, and i Festuca ovina and j Cerastium alpinum occurring at the most productive end of the gradient. Only 10 of the 14 species are shown; there was very little recruitment of the other four species

the natural seed rain. Seed addition markedly increased recruitment, which is not surprising given that seed rain enhancement corresponded to an up to several thousandfold increase in natural seed rain (Duncan et al. 2009).

The results demonstrate in several ways the great importance of the microsite for recruitment. The tight correlation found between natural seed rain density and natural seedling emergence could lead to the misconception that seed rain patterns govern recruitment patterns. However, experimentally sowing a constant number of seeds all along the gradient did not change seedling density patterns. Hence, the relationship between seed rain and seedling densities was not causal. Communities with high seed rain density had vegetation with more important forbs 
and grasses and greater lee effects, which, taken together, provides a good explanation for the higher seed deposition (Chambers 1995a, b; Aguiar and Sala 1997). Welling and Laine (2002) found that seed rain is higher in alpine meadows than in heaths, but the soil seed banks tended to be depleted under meadows, whereas they build up under heaths. This confirms that lack of recruitment in the heath communities is not caused by seed limitation per se. The tiny fraction of seedlings recruiting compared to seeds deposited in traps $(0.25 \%)$ gives yet another indication of the overwhelming importance of the microsite. Removing vegetation and litter layers increased the number of seedlings recorded in the plots from $0.9 \%$ in undisturbed to $11 \%$ of all sown seeds in the disturbed sites, again pointing to the high importance of microsite limitation.

While studies have shown that gaps are important for recruitment in alpine and arctic communities (Chambers 1995a, b; Suzuki and Kudo 2005; Gough 2006; Olofsson and Shams 2007), others have found that seedling emergence and survival is limited on bare soils (Bell and Bliss 1980; Niederfriniger-Schlag and Erschbamer 2000). We expected that the effects of disturbance on recruitment would vary along the environmental gradient, with positive effects of disturbance in more productive sites and negative or neutral effects in low-productivity sites (Grime 1979; Foster et al. 2004). We found no such interaction in our study of the early stages of seedling recruitment.

The importance of disturbance along the entire gradient does, however, indicate that the vegetation and/or litter may limit recruitment. The disturbance induced simultaneous changes in microclimate, light conditions and nutrient availability after removal of the vascular plants, cryptogams and litter, but these changes were minor compared to the natural variation along the gradient and could not explain the large effect of disturbance on recruitment. Litter and moss layers may facilitate seedling establishment, as they provide shelter and humidity, but in small seeded species these layers often constitute a physical barrier for the seeds to overcome before reaching the soil (Sayer 2006; Jeschke and Kiehl 2008). Given the high importance of the emergence phase, we suggest that poor soil contact is an important limitation on seedling establishment in these ecosystems.

We did not find significant interactions indicating differentiation in regeneration niches between species. Some species were indeed more successful than others, but overall recruitment was favored by disturbance and constrained by environmental severity. We saw high mortality of high alpine species such as $S$. acaulis and D. octopetala in the more productive Salix scrub (Fig. 3a, b). Species filtering that was not yet statistically detectable may have started during the second year.
Studies on arctic and alpine seedling recruitment often stress the detrimental effects of harsh winter climate (Körner 2003). Wager (1938) demonstrated that, for arctic plants, about $50 \%$ of individuals that are $<5$ years old die each year, and most seedling survival studies demonstrate decreasing mortality with plant age (Kitajima and Fenner 2000). In accordance with this, around $50 \%$ of the emerged seedlings died during the first year in the present study. We were surprised to find that high winter mortality occurred in the less severe, sheltered sites with abundant snow cover and winter temperatures just below zero. Venn and Morgan (2009) also recorded high winter mortality in plots with high seedling emergence, and suggest that the seedlings had not attained critical carbohydrate thresholds to survive the winter. Other reasons for the high winter mortality may have been physical damage due to movement and compression of the snow or periodical waterlogging. We saw no sign of herbivory in our plots, but fungal attack may have killed seedlings, as abundant snow mold was observed on the vegetation in sites with prolonged snow cover. Soil-borne pathogens may cause high mortality where seedling density is high, since dormant spores of soil-borne fungi germinate preferentially under hydrological regimes similar to those promoting the germination of their host plants (Kitajima and Fenner 2000).

Since the recruitment response along the environmental gradient was clear and similar for both disturbed (experimental seeding) and undisturbed (spontaneous seedlings) vegetation, it is unlikely that the factors driving the recruitment reside in the standing vegetation itself. Rather, our findings suggest that the observed differences are associated with abiotic variation correlated with the vegetation, such as soil moisture, as suggested in other studies (Bell and Bliss 1980; Elberling 2000; NiederfrinigerSchlag and Erschbamer 2000; Welling and Laine 2002; Forbis 2003). Further, we wish to draw attention to the correlation with winter conditions and the high importance of the very early emergence phase during recruitment. High winter temperatures help to break seed dormancy in tundra species (Milbau et al. 2009), and sites with high snow cover stay moist for longer times during the germination phase, providing the right cold stratification conditions (Shimono and Kudo 2005).

While the variation in seed rain and seed banks is of obvious importance for vegetative transitions in changing environments, this is the first study to combine data on natural and manipulated seed availabilities and to demonstrate the very high importance of disturbance and microsite environment for recruitment. From a climate change perspective, changes in herbivore densities that cause important disturbances and changes in snow depths in the microenvironment may greatly influence seedling establishment/recruitment. Though the present study only 
examined the first 22 months after sowing, the observed strong filtering effect of early seedling establishment on final recruitment may have important implications for population dynamics, vegetative transitions and plant migration. The importance of arrival time and the ability to germinate rapidly has been stressed as being an important influence on the final community composition in sowing experiments running for up to 3 years (Ejrnæs et al. 2006; Körner et al. 2008). However, other factors may act as strong filters affecting community composition at later life stages, and long-term studies are needed to test whether the variation in early recruitment observed in our study has the capacity to drive succession.

Acknowledgments This work was supported by a grant from the Danish Natural Science Research Council (21-04-0397) and by ATANS (Access to the Abisko Naturvetenskapliga Station (FP6 506004)). The experiments comply with the current laws of the country in which the experiments were performed. SIL received funding from the Netherlands Organisation for Scientific Research (grant 852.00.070), PTI from the Department of Education, University and Research of the Basque Government (grant BF106.15), and HHB thanks the Danish National Research Foundation for its support of the Center for Macroecology, Evolution and Climate. Thomas Westin is thanked for help in the field, and Lutz Eckstein and the anonymous reviewers for their constructive comments on earlier versions of the manuscript.

Open Access This article is distributed under the terms of the Creative Commons Attribution Noncommercial License which permits any noncommercial use, distribution, and reproduction in any medium, provided the original author(s) and source are credited.

\section{References}

Aguiar MR, Sala OE (1997) Seed distribution constrains the dynamics of the Patagonian steppe. Ecology 78:93-100

Alexandersson H, Eggertsson Karlström C (2001) Temperaturen och nederbörden i Sverige 1961-1990. SMHI Rapport 99 (in Swedish)

Baskin CC, Milberg P, Andersson L, Baskin JM (2000) Germination studies of three dwarf shrubs (Vaccinium, Ericaceae) of Northern Hemisphere coniferous forests. Can J Bot 78:1552-1560

Bell KL, Bliss LC (1980) Plant reproduction in a high arctic environment. Arct Alp Res 12:1-10

Billings WD, Mooney HA (1968) Ecology of arctic and alpine plants. Biol Rev 43:481-529

Brooker RW, Maestre FT, Callaway RM, Lortie CL, Cavieres LA, Kunstler G, Liancourt P, Tielbörger K, Travis JMJ, Anthelme F, Armas C, Coll L, Corcket E, Delzon S, Forey E, Kikvidze Z, Olofsson J, Pugnaire F, Quiroz CL, Saccone P, Schiffers K, Seifan M, Touzard B, Michalet R (2008) Facilitation in plant communities: the past, the present, and the future. J Ecol 96:18-34

Bruun HH, Ejrnaes R (2006) Community-level birth rate: a missing link between ecology, evolution and diversity. Oikos 113:185-191

Bruun HH, Moen J, Virtanen R, Grytnes JA, Oksanen L, Angerbjörn A (2006) Effects of altitude and topography on species richness of vascular plants, bryophytes and lichens in alpine communities. J Veg Sci 17:37-46

Cavieres LA, Badano EI, Sierra-Almeida A, Gómez-González S, Molina-Montenegro MA (2006) Positive interactions between alpine plant species and the nurse cushion plant Larentia acaulis do not increase with elevation in the Andes of central Chile. New Phytol 169:59-69

Cavieres LA, Badano EI, Sierra-Almeida A, Molina-Montenegro MA (2007) Microclimatic modifications of cushion plants and their consequences for seedling survival of native and non-native herbaceous species in the high Andes of central Chile. Arct Antarct Alp Res 39:229-236

Chambers JC (1995a) Disturbance, life-history strategies, and seed fates in alpine herbfield communities. Am J Bot 82:421-433

Chambers JC (1995b) Relationships between seed fates and seedling establishment in an alpine ecosystem. Ecology 76:2124-2133

Chambers JC, MacMahon JA, Haefner JH (1991) Seed entrapment in alpine ecosystems: effects of soil particle size and diaspore morphology. Ecology 72:1668-1677

Choler P (2005) Consistent shifts in Alpine plant traits along a mesotopographical gradient. Arct Antarct Alp Res 37:444-453

Clark CJ, Poulsen JR, Levey DJ, Osenberg CW (2007) Are plant populations seed limited? A critique and meta-analysis of seed addition experiments. Am Nat 170:128-142

Duncan RP, Diez JM, Sullivan JJ, Wangen S, Miller AL (2009) Safe sites, seed supply, and the recruitment function in plant populations. Ecology 90:2129-2138

Ejrnæs R, Bruun HH, Graae BJ (2006) Community assembly in experimental grasslands: suitable environment or timely arrival? Ecology 87:1225-1233

Elberling H (2000) Spatial pattern of Lesquerella arctica: effects of seed bank and desiccation cracks. Écoscience 7:86-91

Forbis TA (2003) Seedling demography in an alpine ecosystem. Am J Bot 90:1197-1206

Foster BL, Dickson TL, Murphy CA, Karel IS, Smith VH (2004) Propagule pools mediate community assembly and diversityecosystem regulation along a grassland productivity gradient. J Ecol 92:435-449

Germino MJ, Smith WK, Resor AC (2002) Conifer seedling distribution and survival in an alpine-treline ecotone. Plant Ecol 162:157-168

Gough L (2006) Neighbor effects on germination, survival, and growth in two arctic tundra plant communities. Ecography 29:44-56

Graae BJ, Ejrnæs R, Marchand FL, Milbau A, Shevtsova A, Beyens L, Nijs I (2009) The effect of an early-season short-term heat pulse on plant recruitment in the Arctic. Polar Biol 32:1117-1126

Grime JP (1979) Plant strategies and vegetation processes. Wiley, Chichester

Grubb PJ (1977) The maintenance of species richness in plant communities: the importance of the regeneration niche. Biol Rev 52:107-145

Jeschke M, Kiehl K (2008) Effects of a dense moss layer on germination and establishment of vascular plants in newly created calcareous grasslands. Flora 203:557-566

Kitajima K, Fenner M (2000) Ecology of seedling regeneration. In: Fenner M (ed) Seeds: the ecology of regeneration in plant communities, 2nd edn. CABI, Wallingford, pp 331-360

Klanderud K, Totland $\varnothing$ (2007) The relative role of dispersal and local interactions for alpine plant community diversity under simulated climate warming. Oikos 116:1279-1288

Körner C (2003) Alpine plant life. Functional plant ecology of high mountain ecosystems. Springer, Heidelberg

Körner C, Stöcklin J, Reuther-Thiébaud L, Pelaez-Riedl S (2008) Small differences in arrival time influence composition and productivity of plant communities. New Phytol 177:698-705 
Krok TOBN, Almquist S (1994) In: Jonsell L, Jonsell B (eds) Svensk flora, 27th edn. Liber, Stockholm

Lindgren $\AA$, Eriksson O, Moen J (2007) The impact of disturbance and seed availability on germination of alpine vegetation in the Scandinavian mountains. Arct Antarct Alp Res 39:449-454

MathSoft (1999) S-PLUS 2000, professional release, 2nd edn. MathSoft, Seattle

McCune B, Grace JB (2002) Analysis of ecological communities. MjM Software, Gleneden Beach

McCune B, Mefford MJ (1999) PC-ORD. Multivaritae analysis of ecological data, v.4.41. MjM Software, Gleneden Beach

Milbau A, Graae BJ, Shevtsova A, Nijs I (2009) Effects of a warmer climate on seed germination in the subarctic. Ann Bot 104:287-296

Molau U, Larsson EL (2000) Seed rain and seed bank along an alpine altitudinal gradient in Swedish Lapland. Can J Bot 78:728-747

Moles AT, Westoby M (2004) What do seedlings die from and what are the implications for evolution of seed size? Oikos 106:193-199

Myers JA, Harms KE (2009) Seed arrival, ecological filters, and plant species richness: a meta-analysis. Ecol Lett 12:1250-1260

Niederfriniger-Schlag R, Erschbamer B (2000) Germination and establishment of seedlings on a glacier foreland in the central Alps, Austria. Arct Antarct Alp Res 32:270-277

Olofsson J, Shams H (2007) Determinants of plant species richness in an alpine meadow. J Ecol 95:916-925

Ripley BD (1996) Pattern recognition and neural networks. Cambridge University Press, Cambridge

Sala OA, Chapin FS, Armesto JJ, Berlow E, Bloomfield J, Dirzo R, Huber-Sanwald E, Huenneke LF, Jackson RB, Kinzig A, Leemans R, Lodge DM, Mooney HA, Oesterheld M, Poff NL, Sykes MT, Walker BH, Walker M, Wall DH (2000) Global biodiversity scenarios for the year 2100. Science 287:1770-1774

Sayer EJ (2006) Using experimental manipulation to assess the roles of leaf litter in the functioning of forest ecosystems. Biol Rev 81:1-31
Shevtsova A, Graae BJ, Jochum T, Milbau A, Kockelbergh F, Beyens L, Nijs I (2009) Critical periods for impact of climate warming on early seedling establishment in subarctic tundra. Glob Chang Biol 15:2662-2680

Shimono Y, Kudo G (2005) Comparisons of germination traits of alpine plants between fellfield and snowbed habitats. Ecol Res 20:189-197

Stevens MHH, Bunker DE, Schnitzer SA, Carson WP (2004) Establishment limitation reduces species recruitment and species richness as soil resources rise. J Ecol 92:339-347

Suding KA, Goldberg DE (1999) Variation in the effects of vegetation and litter on recruitment across productivity gradients. J Ecol 87:436-449

Suzuki S, Kudo G (2005) Resource allocation pattern under simulated environmental change and seedling establishment of alpine dwarf shrubs in a mid-latitude mountain. Phyton-Ann Rei Bot 45:409-414

Tielbörger K, Kadmon R (2000) Temporal environmental variation tips the balance between facilitation and interference in desert plants. Ecology 81:1544-1553

Turnbull LA, Manley L, Rees M (2005) Niches, rather than neutrality, structure a grassland pioneer guild. Proc R Soc B Biol Sci 272:1357-1364

Venn SE, Morgan JW (2009) Patterns in alpine seedling emergence and establishment across stress gradient of mountain summits in south-eastern Australia. Plant Ecol Divers 1:5-16

Wager HG (1938) Growth and survival of plants in the Arctic. J Ecol 26:390-410

Welling P, Laine K (2000) Characteristics of the seedling flora in alpine vegetation, subarctic Finland, I. Seedling densities in 15 plant communities. Ann Bot Fenn 37:69-76

Welling P, Laine K (2002) Regeneration by seeds in alpine meadow and heath vegetation in sub-arctic Finland. J Veg Sci 13:217-226

Zuur AF, Ieno EN, Walker N, Saveliev AA, Smith GM (2009) Mixed effects models and extensions in ecology with R. Springer, New York 